\title{
Um caso de Pangenitalite cronica com surto agudo tratado com as vaccinas antigonococcicas e antipiogenas Bruschettini
}

A observada, Mme. A. R., com 24 annos, branca, brazileira, queixava-se de fortes dores na região hypogástrica com irradiação para ars fossas iliacas. Achava-se acamada, quando fomos chamados para examinaita em sua residencia.

Referiu-nos que ha dois annos teve um corrimento purulento, esverdinhado, que exudava pelos órgãos genitais externos. Algum tempo depois rsentiu fortissimas dores em todo baixo ventre, obrigando-a a ficar no leito por espaço de vinte dias. Consultou-se com um facultativo que lhe prescreveu lavagens de permanganato de potassio e lhe conselhou tratamento cirurgico. Fez uso das lavagens e, como melhorasse, não se quiz submetter a intervenção cirurgica.

o fluxo purulento continou ora com maior, ora com menor intensidade. Em janeiro do corrente, teve um surto agudo com repericussão sobre todo o aparelho genital. Fomos chamados n'essa occasião. A doente estava com $39^{\circ}$ de temperatura. Fizemors o exame ginecologi$c_{0}$ e verificamos: vaginite, metrite salpingo-coforite dupla.

Como se tratava de caso cronico, onde, certamente, outros germens, alem do gonolcocco, deveriam estar presentes, empregamos: Vaccinas Antigonococcicass e Antipiogena de Bruschettini, feitas alternadamente, applicação tópica de calor, e aconselhamos repouso absoluto .

$\mathrm{Na}$ quarta vaccina, vale dizer, depois do emprego de duas Antigonococcicas ie duas Antipiogenas, achavatise a nossa doente muito me. lhorada: as dores espontaneas haviam cedido por completo, o corrimento muito diminuido, a temperatura normal, volta do apetite e o estado geral satisfatorio.

Na decima injecção a doente não tinha mais corrimento, não havia mais hiperalgia da parede abdominal anterior. Sómente os pontos ovaricos pouco sensiveis á pressão. Aliáłsi, a menstruação da nossa paciente, segundo nos informou, foi sempre precedidas de cólicas ovarianas, e o fluxo catemenial era esperado nessa occasião pela doente.

Nos casos de metrite aguda, ou mesmo nas metrites crónicas com surto agudo de salpingite ou salpingo-coforite-como no caso da nosisa observada, em que as grandes lavagens são contraindicadas, bem como as embrocações tópicars no endometrio, costumamos, de pariceria com repouso absoluto, applicações de calor e anódinas, prescrever as "Vaccinas Antigonococcicas de Bruschettini", ou a Antigonococcica, alternada com a Antipiogena nos carson cronicos.

\section{DR. NERY MACHADO.}

Da Faculdade de Medicina do $\mathrm{Ri}_{0}$ de Janeiro. 